\title{
Clinical legal education and Indigenous legal education: what's the connection?
}

\author{
Anna Cody1 and Sue Green ${ }^{2}$
}

\section{Introduction}

In this article 3 we will examine some of the steps that UNSW law school has taken to address Indigenous disadvantage in, and exclusion from, legal education. The article focuses on the role of clinical legal education within Indigenous legal education. Two concrete examples will be discussed: a clinical subject specifically designed for 1st year Indigenous students and a class given by an Indigenous academic for later year law students within the general clinical legal education courses. The first is discussed to demonstrate how clinical legal education can improve the experience of Indigenous students within law schools. The second example highlights the challenges of attempting to "Aboriginalise" the curriculum of law courses.

\section{Kingsford Legal Centre: clinical legal education and a commitment to social justice}

Kingsford Legal Centre hosts the clinical legal education course of the University of New South Wales' Law School. Since its beginning UNSW Law Faculty has emphasised social justice within law and studying law in a social, economic and political context. The Centre was established in 1981 specifically for the purpose of grounding the education at the Faculty of Law in social justice. The legal education at UNSW, in contrast to the University of Sydney, was characterised by small group teaching that was critical of the legal system around it, and accessible to the community. Community service as a part of the teaching program was seen as a valuable and essential part of legal education.

1 Senior Lecturer of Faculty of Law UNSW and Director Kingsford Legal Centre

2 Associate Professor of Faculty of Social Sciences and Director Nura Gili.
3 We would like to thank the anonymous reviewer and Meena Sripathy for comments about this article. 


\section{Commitment to Indigenous legal education}

As a part of this social justice focus, UNSW has long been committed to Indigenous legal education. A pre-law course for Indigenous students commenced as far back as 1995. That year also saw the foundation of the Aboriginal Law Centre, now the Indigenous Law Centre. In late 2002 an Indigenous legal education committee (ILEC) ${ }^{4}$ was established. The aim of this committee is to examine and address some of the barriers that Indigenous students face in entering law school and to create programs to address these. ${ }^{5}$ An alternative access and preparation scheme has been developed with the aim of recognising the difficulties that Indigenous students have traditionally faced in secondary school. By their participation in this committee, members of the Commitee have been encouraged to look at the courses which they teach and examine how Indigenous issues are dealt with within their curriculum. This will be discussed later in looking at how the Foundations Enrichment 2 course functions, as well as the clinical subjects taught at KLC.

\section{Foundations enrichment 1 and 2}

Two further key developments within the UNSW Law Faculty are the inclusion of two subjects specifically for first year Indigenous students: Foundations Enrichment 1 and Foundations Enrichment 2. These courses are aimed at supporting first year students once they have been accepted into studying law.

Research has shown that Indigenous students find the experience of law school alienating and disorientating. In the words of Indigenous students:

"the problem is that you are disorientated by the system...there is no two way learning you are just talked at, that disorientates you even worse...

I don't know how you can stop people dropping out...the thing they can do is not make it such an alien environment...

I feel under siege in the classrooms...6

ILEC suggested specific measures to address these experiences, having regard to current research and guided by Nura Gili, Indigenous Programs Centre. Foundations Enrichment 1 is run in conjunction with staff from the UNSW Learning Centre and offers Indigenous students a weekly small group tutorial. Its primary purpose is to develop students' academic skills, including oral communication, problem solving, comprehension and legal writing skills. It also works to develop their critical and analytical skills. ${ }^{7}$ It gives the students a chance to be with each other, in the majority, rather than a minority within a larger classroom setting. Although not formally evaluated as yet, it appears to be functioning effectively as a means of support for Indigenous students. As Penfold and others have found in their studies of what contributes to the success of Indigenous students at law schools, the "opportunity to network with other Indigenous students"8 is vital. The support provided by Nura Gili is an essential part of the networking and support mechanisms. The course helps students adjust to the academic requirements and social context of studying law.

4 Both authors are members of this committee.

5 The work of this committee has been described in detail elsewhere in the Indigenous Law Bulletin: Brennan S, Hunter J, Healey D, Johnson D, San Roque M, Wolff L, "Indigenous Legal Education at UNSW: a work in progress" (2004) 6(8) Indigenous Law Bulletin pp26-29
6 Comments of students quoted in Douglas $\mathrm{H}$, "Indigenous Legal Education: Towards Indigenisation” (2004) 6(8) Indigenous Law Bulletin, p2

7 Brennan et al, above n 2, 4.

8 Penfold "Indigenous Students' perceptions of Factors contributing to Successful Law Studies" (1996) 7(2) Legal Education Review 
Another issue identified by Indigenous students interviewed in Queensland and reported by Douglas and Banks, is the lack of relevance of the material that students are confronted with on beginning their legal studies. One student commented:

"The first subject was contract, it was so incredibly boring and it is the first thing you have to do and there is all this other stuff that you have to get used to and I was thinking I don't really care. You lose it from the beginning if you don't care. If I had a tutor there straight away to explain, it may have been different."9

This is an issue for all students on beginning law, 10 but appears to have a greater impact on Indigenous students. The value of clinical legal education for addressing this apparent lack of relevance of material was recognised by ILEC and led to the development, among other measures, of the clinical course for first year Indigenous students: Foundations Enrichment 2. This course is based at Kingsford Legal Centre and offers Indigenous students a clinical experience in the first year of their law studies. From the evaluations of other clinical subjects offered at the Centre, many students comment on the value of seeing law in practice and the benefit it offers them to analyse the law and legal system in context rather than abstractly through a text book. The exposure to real clients early on in their degree provides a level of 'analysis in practice' which ideally all law students should have access to but which is almost impossible to provide, from a resource perspective, except to limited numbers, in this case 1st year Indigenous students.

Indigenous students are not required to do both these subjects. They choose to enrol in them for academic credit, and do one less elective as a result. At this point students appear to appreciate the availability of extra support rather than resist it. It gives them the opportunity to be only with Indigenous student peers. For all their other courses they are in mainstream classes with all other students.

The course focuses on developing the students' oral and written communication skills through interviewing. They have access to a one to one mentoring relationship with a clinical student who is in the latter stages of their degree. The mentors assist by discussing one of their files with the first year student. While the Indigenous students evaluate the course, the impact of mentoring on clinical students has not been specifically evaluated. Informal comments from these students suggest that they enjoy the opportunity to share their knowledge and experience and talk with Indigenous students. It also provides an opportunity for them to get to know Indigenous people which some of them may not have had the chance to do before this course.

In addition, the students participate in visits to key agencies which introduces them to the legal aid system and how it functions. The purpose of these activities is to demonstrate how their studies may be relevant in the future and expose them to possible future careers options.

The visits include a talk with the registrar and magistrate at a Local Court, where they also sit in court and listen to a case. This is frequently the first time they have actually seen the legal system in action from a disinterested perspective. Many may have some experience of the legal system

9 Douglas H \& Banks C, "From a Different Place Altogether: Indigenous Students and Cultural Exclusion at Law School," (2001-2002), 15, Australian Journal of Law and Society, p56

10 Other mechanisms such as the Peer Tutor program has been developed to provide support to first year students at UNSW. See Fitzsimmons, Kozlina, Vines "Optimizing the first year experience in law: the law peer tutor program at the University of New South Wales" (April 2007) Legal Education Review. 
through family members or friends coming into contact in some way. ${ }^{11}$ They are asked to write a short court report of their experience to encourage reflection and develop their writing skills. They also visit the Public Defenders office, the Legal Aid Commission and the pro bono section of a large law firm. One class is dedicated to visits from community legal centre lawyers and other public interest lawyers who describe their work and encourage the students to think of possible career options outside the traditional law firm. All of these activities encourage a more concrete examination of what is possible with both law and a law degree.

\section{Flexibility in delivery}

It should not be surprising that well documented research of higher sickness and mortality rates for Indigenous peoples also impact on students' ability to participate in tertiary education. "[Indigenous] students are more likely to be sick or to have a direct family member who is sick and in need of care or hospitalisation than a non-Indigenous student. University teachers need to keep these considerations in mind when an Indigenous student is frequently absent from class; has not done their readings; is looking for an assignment extension or a deferred exam; or simply has not filled in a required form." 12

In this context, the timetabling procedures for the Foundation Enrichment courses were designed specifically with flexibility in delivery of the courses for indigenous students in mind.13 Whereas other subjects are centrally timetabled, for this course students are individually contacted to work out the best time for the class. This consultative process sets a tone of informality and flexibility within the course. It also demonstrates the teacher's interest in each of the students and a desire to accommodate specific students' needs.

For example, in 2005, one of the students had considerable outside work commitments. This work involved him interviewing clients and therefore, taking account of the overlap with course content, he was granted some advance standing to allow him to participate in the course. In 2006, another student who had clashing work commitments and a very full law enrolment was given exemptions from classes by recognising his prior experience. In this way, a more flexible approach is taken for these students to maximise their participation in this course. Also, because of the small size of the group it is easier to maintain personal contact and address any attendance issues immediately.

The evaluations of the Foundations Enrichment 2 course since it has been in operation have been overwhelmingly positive. To the question "how will this course influence your later studies?" student responses have included:

- The fact that we have had the opportunity to do things that other first year students haven't been able to do

- It helps me realise that all of the theory in class will pay off when we deal with real law situations

11 Falk discusses how many Indigenous people will have had some contact with the criminal legal system and Green has commented on the intrinsic intrusiveness of the legal system into Indigenous people's lives through the welfare system among other areas.

12 Falk P, "Law School and the Indigenous Student Experience”, (2004-2005), 6(8) Indigenous Law Bulletin, p8
13 MacAulay discusses the importance of flexibility and creativity for successfully improving access to legal education for Native students in MacAulay $\mathrm{H}$, "Improving Access to Legal Education for Native People in Canada: Dalhousie Law School's I.B.M Program in Context", (1991) 14(1) Dalhousie Law Journal, p 146 
- It will be beneficial in helping to locate and analyse legal issues in scenario based problems throughout my studies

- I now know that I'm definitely staying in studying law ${ }^{14}$

- It reminded me why I started law in the first place, to give aid, and advice to those who are in need or who have been given a rough run

- Probably guide me into working for a legal centre, not private

- Gives a better understanding of application of the law to real life scenarios ${ }^{15}$

- Greater knowledge of clients, more insight as to what I want to take from law school, a different point of view outside the theory of academics

- Good practical experience, gives us greater knowledge

- I know it will have enormous influence if I receive a job which I have applied for over the summer break with Law Access. I am more confident speaking to people

- We are lucky to have an understanding of the law in a more practical way. Something the other students might never get to see unless they pursue a career in this area

- Doing Law Lawyers - will be well prepared! We are also well equipped to gain employment as a law clerk later on, and also have contacts in the legal industry etc ${ }^{16}$

The course clearly provides gives these students with a grounding and motivator for their legal studies. The student responses demonstrated that they appreciated the opportunity to have access to a practical application of law at this early stage and that this helped them stick with their law studies.

Students were also very enthusiastic about the experience of interviewing clients in advice sessions, and the exposure to clients from different cultural and other backgrounds., Student comments about the experience of interviewing multiple clients on an advice evening session included:

- "It's awesome, the whole course came together in this session",

- "this was the highlight of the course as it was really interesting and a really great experience",

- "once again excellent, I was able to interview a client by myself with the assistance of a translator",

- "great experience being able to work with different cultures..."

- "Loved it! Felt that I really helped and enjoyed the process of finding out about laws - not just regurgitating knowledge".

Responses in the evaluations demonstrate the value that students gain from the course. They identify that they become recommitted to social justice or helping people through their interviewing experience. They gain a sense of confidence in their ability to interview effectively and well. They see the possibilities for themselves and their communities in them studying law and having a law degree.

14 Evaluations of FE 2 course in 2004

16 Evaluations of FE 2 course in 2006

15 Evaluations of FE 2 course in 2005 


\section{Positive evaluations typical of clinical legal education evaluations?}

To a large extent, these sorts of responses are typical of clinical student evaluations of any clinical legal course. One could argue that ALL law students should do some clinical legal course early on in their degree. This is unlikely to occur however due to the resource implications for providing clinical legal education. Furthermore where there are limited resources, due to the documented greater likelihood of Indigenous students withdrawing from legal studies, it is important to target those limited resources to ameliorate this problem. Traditionally, law schools have found it harder to attract and retain Indigenous students. It is therefore more important for Indigenous students to have the opportunity to do clinical courses early in their degree program. These evaluations could also suggest the value of providing some clinical experience to other disadvantaged students who may be at risk of withdrawing from their studies. Ideally ALL students would do more clinical work/study early on but from a resource perspective this is unlikely to be realized at UNSW.

At this point, the provision of a clinical course specifically for Indigenous first year students does not appear to have caused any resentment amongst the greater student body. This hasn't been raised directly by any non Indigenous students possibly because they are unaware of the course. The numbers of students enrolling in the course each year are small, between five and seven students. Additionally, KLC offers interviewing experiences to almost all legal ethics students in 1 st, 2 nd or 3rd year. Overwhelmingly the students in their reflective assignments in this course discuss the value of dealing with real client's problems and how interviewing clients grounds their theoretical study. They also state how this has stimulated them to take clinical courses later in their degrees.

\section{Challenges in teaching the course}

From a teaching perspective, one of the challenges thrown up by this course arises from the divergence in level of capacity among the student group. While this is an issue with any course, the differing levels of ability and confidence have more of an impact in a small group. Some students have more experience and confidence interviewing clients than others. This is demonstrated by the ability of the students to put clients at ease and enable them to tell their stories fully, a skill which is key to good instructions in a legal setting. Writing skills is another issue for some students, particularly those who may have had a more difficult time at secondary school. To meet this need, the course was modified to provide greater emphasis on the written redaction of instructions and a court report. We have found that it is necessary to be creative and flexible for the course to be appropriately "useful for all of the students all of the time". ${ }^{17}$ For example in one of the classes the students are required to interview a real client for the first time in pairs. In 2006, one of the students was clearly capable and keen to interview the client by himself and was permitted to do so. He was also allocated a potentially more challenging client who had a psychiatric disability and various legal issues in the evening advice session. In this way, the course is responsive and accommodates each individual student.

Judging from the levels of achievement of the Indigenous students as they progress in their legal studies and their own evaluations of the courses, the Foundations Enrichment 1 and 2 courses and other measures taken by the UNSW Law faculty are working to help students continue successfully with their legal studies. The alienation felt by Indigenous law students expressed in

17 MacAulay, above n 12, 151. 
earlier research is to some degree being ameliorated through the courses developed at UNSW. This is through the course content, including the fostering of mentoring relationships with later year non Indigenous students. The Foundations Enrichment 2 course was developed to improve the experience of Indigenous students at law school, particularly in their first year. By providing a clinical legal experience early on in their degrees, Indigenous students are better able to participate in their law degrees. While there is always room to evaluate and improve, the courses are an effective means of ensuring that Indigenous law students enjoy their legal studies and are able to participate fully in a relevant, enjoyable course of legal studies that is inclusive of Indigenous views of the world. Support beyond first year is generally provided through the Nura Gili Centre rather than through law-specific courses. Many of the students accept cadetships with government and law firms which provides them with ongoing practical exposure. Need for additional support is an issue which remains to be discussed further within ILEC.

The other need identified by ILEC and after the symposium on Indigenous legal education in 200418 was the need to review and change the curriculum of all courses to reflect Indigenous experiences and views of law. This is an attempt to "Aboriginalise" the curriculum in all courses. It is not enough to provide a supportive learning environment for Indigenous students, we must also think about the broader curriculum and how this alienates Indigenous students and deals with Indigenous issues. ${ }^{19}$ This involves critically evaluating how we structure law courses as well as their content. This has the potential to be challenging for all students and Faculty. It is yet to be done throughout all courses within law. With this in mind, in 2005, KLC decided on various measures to incorporate Indigenous issues within the clinical courses. These courses are taken by almost entirely non-Indigenous students. In the next part of this article we describe the class on working with Indigenous clients and communities, which was developed as a part of the attempt to review and improve the class content.

\section{Clinical legal education course for later year non-Indigenous law students}

Teaching the later year non-Indigenous clinical students about Indigenous issues is perhaps more of a challenge than teaching the Foundations courses. Many students have clear ideas about what it is to be Indigenous and the place of Indigenous people and issues within Australia. The students would have had exposure to issues that have come up in the last decade such as the Stolen generation and the impact that Aboriginal children being removed has had on current generations of Aboriginal people; the treaty debate, representation of Indigenous people in custody and deaths in custody of Indigenous people; and domestic violence and sexual assault in Indigenous communities.

As well as teaching law students, KLC is a community legal centre providing legal services to its local community which includes the Randwick and Botany council areas. This catchment area includes the Indigenous community at La Perouse. The Centre advises and represents Indigenous

18 Kingsford Legal Centre and the Indigenous Legal Education Committee organised a symposium on Indigenous legal education in November 2004 at UNSW to discuss issues within the region relating to Indigenous legal education.
19 See Falk footnote above, also Watson, I, "Reflections on Teaching Law: Whose Law Yours or Mine?" (2005) 6(8) Indigenous Law Bulletin, p12, and Kelly L, "Personal Reflection on being an Indigenous Law Academic", (2004-2005), 6(8) Indigenous Law Bulletin, p3 
people (approximately $2 \%$ of the clients at KLC are Indigenous) and is currently establishing an outreach service to better serve the Indigenous community. KLC is actively committed to improving and adapting the service it offers to better serve its Indigenous community. 20 It has actively sought funding for an Aboriginal cadetship program within community legal centres. At the end of 2006 the Combined Group of NSW community legal centres was successful in obtaining funds from the Public Purpose Fund NSW to establish an Aboriginal legal access program.

Following the November 2004 symposium, KLC realised the importance of students learning about working with Indigenous clients and communities from an Indigenous perspective. The majority of the students who enrol in courses at KLC are from relatively middle-class, though increasingly culturally diverse, backgrounds. Many are committed to social justice but would not have had much to do with Indigenous people before starting their course at KLC. The seminar program contains a mixture of classes given by staff at KLC and other guest lecturers. It includes classes on the provision of legal aid and community legal services, plain English drafting, discrimination law, working to settlement in conciliations, how to deal with challenging clients, employment law, law reform and human rights amongst others. They include substantive areas of law as well as more skills based classes.

The seminars are the only time in which all 30 of the enrolled clinical students are together. Historically the classes are structured to be participative with many small group exercises and discussions. Students are given a class program and readings in their induction in Week 1 of their course. As a part of the measures KLC has adopted to improve the service for Indigenous clients and students, KLC acknowledges the traditional owners of the land KLC is on at the beginning of the first class of each semester. Clinical supervisors in their individual supervision regularly discuss issues with students, including how their view and solicitors' views of clients may be influenced by cultural and racial stereotypes and how this may influence their work. In the class program there is a class which addresses the topic of working with Indigenous communities and clients. The readings in preparation for this class focus on the skills needed when interviewing Indigenous clients.

In the next section of this article we describe two experiences of giving this class and a reflection on how to best address these issues.

\section{The class in $2005 / 06$}

When the class was presented in summer 2005/06, the clinical teacher gave a brief introduction of Sue Green, Director of Nura Gili, Aboriginal Resource Centre at UNSW. Sue Green then gave a presentation, using her life history and family history as a means of demonstrating experiences of Indigenous people. She described the extensive language groups existing in Australia at the time of white invasion and showed pictures of her family members and family tree, as well as pictures of passes which her family members had to carry to be allowed to leave the Reserve they lived on. In the second half of the class she answered questions about alcohol use and abuse, why she identified as Aboriginal despite having light coloured skin among other issues.

The following day within the larger student working space a fairly heated discussion began amongst

20 ATSI access policy, KLC. 
about eight of the students, about the class the previous day. Some students were critical of Sue for using the word "genocide" when referring to the policies towards Indigenous peoples which had been adopted since white invasion. Others struggled with her identifying as Aboriginal rather than her other cultural identities and thought she was a "victim". Some were strongly supportive of her and focussed on the parts of Australian history they had known nothing about previously. Others were critical of her being "negative" and not doing anything positive in the community to improve the situation of Indigenous people. They referred to her adopting a "victim" stance and questioned her contribution to Indigenous communities and the society at large.

At the beginning of the next class the clinical teacher referred to the previous class and the overheard discussions which had occurred later. There then was a frank discussion with people having quite differing views of the class. Some wanted clearer guidelines on "how to work with Indigenous clients", a succinct list of "what to do". Others were critical of this, stressing the need to deal with each Indigenous client individually. One of the students referred to his grandmother having lived through the holocaust and how this frames her world view. He used this experience to understand why Sue Green used the term 'genocide' when she discussed what has happened to Indigenous peoples.

At the conclusion of the discussion, the clinical teacher described Sue's credentials and achievements. She referred to the fact that Sue Green is an Associate Professor within the University and how constructively she works within the University to ensure Indigenous students get to University and successfully complete their studies. She also talked about different ways of talking and seeing the world and that while law students are used to analysing cases logically, narrative is an equally valid way of seeing and describing the world. Sue had demonstrated what it was like to be Indigenous as opposed to providing a simplistic a list of do's and don'ts for dealing with Indigenous clients.

Following the class we reflected on the students' reactions and responses and decided to try a different introduction to the class next time. It was clear from this experience that the students weren't prepared for a speaker to present differently and came laden with their views about Indigenous people and race issues within Australia more broadly.

"Describing to non-Indigenous students the concept of an Aboriginal worldview is difficult, but so is the Aboriginal experience of colonialism, and apart from providing students with my perspective along with those of other Aboriginal guest lecturers, contact with Aboriginal community organizations and the extensive readings by Aboriginal writers, I still find nonAboriginal students struggle to engage with the idea of a different view of the world and the Aboriginal experience of racism and colonialism. It is difficult for the non-Aboriginal student to engage because the Aboriginal question sits outside of any of their experiences." 21

This clearly resonated with our experience in this class.

Unfortunately the class program was not formally evaluated that semester due to an administrative error. Informally many students commented to the teacher about the value of both the class and the discussion afterwards for helping them to understand some Indigenous issues better.

21 Watson I, "Reflections on Teaching Law: Whose Law Yours or Mine?” (2005) 6(8) Indigenous Law Bulletin, p12 


\section{The class in Session 12006}

The following semester a different approach was taken to present this class.

This time, the clinical teacher introduced the guest lecturer, Ms. Sue Green as an Associate Professor of the University. The work of Ms. Green's Nura Gili Centre and its achievements in relation to Indigenous students was described. The clinical teacher also discussed different ways of learning and teaching other than case analysis and talked specifically about the story telling or narrative style which is discussed and used substantially within critical race theorists in the United States of America. The point was to frame the class and the students' expectations of it in light of the previous group's reaction.

The class that Sue presented was substantially the same as the class she had given previously. Discussion flowed easily and students asked questions and explored some of the issues.

After the class, there was no heated discussion in the student area about it, other than students commenting how much they had learnt and enjoyed the class. The class was formally evaluated by 24 students. Of the 24, 12 found it very interesting and relevant, 10 found it interesting and relevant and 2 made no response. No-one thought it was "not interesting or relevant". Of all the classes, this was the class that received the most positive responses and was found to be most interesting and relevant.

Students' comments included:

- I didn't agree with everything she said, but I guess that is a good thing

- I really found her experiences very interesting and insightful

- These 2 classes (Indigenous class and pleamaking) were my favourites. Sue Green was fantastic and so was the lady from Blakes

- Great presentation. Created a lot of interest from all students

- This was the most interesting of all classes

- That woman is amazing and an inspiration.

The difference in response between the two groups of students was marked. It raised for us a number of interesting questions: Were the differing responses due to the personalities and identities of the students or was it due to the way in which the class was introduced? Did the specific emphasis on Sue's academic credentials given in the introduction to the subsequent class make the students more open to hear what she had to say?

We now discuss some observations from the divergent experiences of these two classes.

\section{World view challenged and impact of personal identities}

Having an indigenous presenter for this class appears to challenge the students' world view. Some students like it and others don't. Some of the students have the view that by being law students, they are bright, have progressive, community-service-based motives and find it hard to be challenged around race issues. Some of the students at KLC probably see themselves as being socially aware and even radical and for this reason confronting their identities may be more difficult. 
"The relationship of Indigenous people to the Anglo-Australian legal system is something that goes to the heart of legal process and legal theory. It constructs our national identity and can even impact on the personal identity of non-Indigenous Australians. How we deal with that history (remembering that history is everything that has happened before this moment) challenges who we are." 22

The divergent experiences of this class suggest that students find the challenging of their conceptions of themselves confronting. We need to encourage students to be conscious of their own personal identities and how this impacts on their lawyering. KLC's clinical course addresses this in the areas of interviewing and direct individual supervision of case work, but not in formal classes. The discussion of how their identities may impact on their ability to assist Indigenous clients and communities needs to be raised forcefully and directly. An Indigenous academic presenting a class gives an opportunity for students to hear an Indigenous voice who is not the needy client. The class implicitly questions students' identities but this may need to be made more explicit.

It may be useful to add a separate seminar class in which we question and discuss:

How will my cultural background, class, gender, sexuality impact on my ability to assist my client?

Is an Indigenous lawyer more likely to be able to help an Indigenous client?

Can a non-Indigenous lawyer develop a rapport with Indigenous clients?

It may be useful to ask students who are working with Indigenous clients to reflect on their experience within the class setting. These discussions arise in an informal way currently in morning tutorials in which larger questions about the fairness of the legal system arise. Frequently students are confronted with the huge difficulties which Indigenous clients face, health problems, lack of education, family obligations and the ways in which this makes it more difficult to claim legal rights or pursue legal remedies. These issues haven't been teased out more formally but rather arisen in a more informal way and in individual supervision with clinical teachers.

Another shift in the last one to two years is the experience of non Indigenous students working closely with Indigenous students enrolled in the clinical courses. As the clinical experience encourages team work, and close working relationships, this again provides an opportunity for students to develop relationships and links which they may not have previously. Hopefully this contributes to breaking down stereotypes. Generally for Indigenous students to have reached final year of law they are high achievers in their communities who are articulate, committed, active and hard-working. This contradicts stereotypes of Indigenous people as victims who are unable to deal with their communities problems.

Ideally these classes should be co-taught with an Indigenous teacher to ensure a range of inputs and perspectives. Currently none of the clinical teachers are Indigenous thus do not bring this perspective to their work. They bring a range of cultural backgrounds and other forms of diversity to their work. These issues could all be explored more fully as well as the diversity of the student body.

22 Kelly L, "Personal Reflection on being an Indigenous Law Academic", (2004-2005), 6(8) Indigenous Law Bulletin, p3 
Another broad reason for teaching personal identification issues in lawyering courses is that lawyers, as people who deal with the public professionally, should demonstrate leadership and set examples of tolerance and pluralism. The importance of being non-judgemental in our work is discussed from induction, through individual case discussions, interviews and morning tutorials. The need for tolerance and pluralism can be especially important for public interest lawyers whose clients are from subordinated communities, as these communities stand to gain the most from respect of difference and diversity. ${ }^{23}$ When students are judgemental about clients, for not taking action sooner, for "lying", for being "victims", clinical teachers question these points of view. Frequently as the student gets to know the client better, their immediate judgements soften and are often proved wrong. This provides rich ground for discussion and analysis, and encouraging tolerance and non judgemental attitudes towards clients.

\section{Talking about race}

Another observation from the experiences of these classes is that it may be easier for students to see Aboriginal people as needing help in the role of a client. A presentation by an Aboriginal female Associate Professor subverts the roles and expectations of students even if they are unarticulated. To point out to students that there is a race issue in Australia disturbs people. If you are in the dominant cultural group it is often easy not to see the race issue. It would be easier to have a "checklist of simplistic cultural stereotypes" 24 on "how to deal with Indigenous clients and communities" than a discussion of racism in Australian society. It may be more useful and also more challenging for us as teachers to encourage students to interrogate their cultural and other identities. The class asks them to be aware of their own ethnicity and race. We need to help them recognise what they don't know rather than use stereotypical lists.

\section{Use of narrative as a style of teaching}

The class uses a narrative style of teaching. Students are not accustomed to learning in a university setting, without "academic-speak". Using everyday speech rather than an academic style means students may value the content less.

Narrative is excluded from traditional law teaching. Critical race theorists in the USA have commented extensively on the importance of story for the inclusion of minority voices within law. 25 Indigenous scholars in Australia also recognise the importance of narrative. As Kelly writes "Story -telling is a huge part of my traditional culture so I'll take this opportunity to tell a bit of my story... even though writing "in the narrative' is not so acceptable in legal scholarship." 26 The difficulty the later year law students had with dealing with narrative as a form for learning was striking. This made us question how to teach the class. We asked, "Do students need to be prepared to hear narrative, rather than a logical case analysis?" or should they be allowed to experience the class, without being prepared and allowed to respond however they do?

23 Hing B O, "Raising Personal Identification Issues of Class, Race, Ethnicity, Gender, Sexual Orientation, Physical Disability, and Age in Lawyering Courses", (1993), 45(6) Stanford Law Review, p1810

24 O'Donnell A, “Thinking Culture in Legal
Education", (1996),7(2) Legal Education Review, p152

25 Delgado R, Critical Race Theory: The Cutting Edge, (1995) Temple University Press: Philadelphia

26 Kelly, above n 19, 1. 


\section{Cultural diversity of students}

The student body at UNSW is increasingly culturally diverse. The student body is no longer predominantly made up of Anglo Saxon white Australians. There are many Australian born students from culturally and linguistically diverse backgrounds. There is also a growing international student body, with many students coming from economically privileged backgrounds in South East Asia. These students may be culturally in the minority in Australia and have experienced racism here, but have not grown up in a culture where they are disadvantaged or in the minority.

Many of the international students may not necessarily have been aware of Indigenous issues in Australia before coming here. Once they have been here a while, they will have been exposed, through the media, to various Indigenous issues but will probably have not met Indigenous people and thus their views are more likely to be shaped by stereotypes rather than reality.

Students of more recent non-Anglo migrant background may have views which have been influenced by their parents' ability to "make it" in Australia. The fact that these students belong to a minority group and may have experienced discrimination and marginalisation along the way, does not mean that they will necessarily understand or connect with the circumstances of Indigenous people who occupy a very specific and historical position of disadvantage in this country.

It may be useful to question more broadly issues of "culture". Some have argued that Australia is "a society with a multicultural population, regulated and governed by a mono-cultural power structure." 27 Rather than just focussing on cross cultural awareness, it is important to raise a larger pedagogical question "in which relations of power and racial identity become paramount as part of a language of critique and possibility." We need to question, what is culture and challenge the notion of it as static and unchanging. "A view of culture and ethnicity that sees them as static and unchanging will also tend to attribute a homogeneity to cultures that obscures important differences of class and gender within recognised "ethnic communities" or commonalities of interest across communities." 28 The range of students from diverse cultural backgrounds would be rich material for discussion around "what is culture" and "how does it impact on our work".

The class has much scope to discuss culture/race as formative of identity within a range of experiences. A broader discussion about culture as one of the identities we all have would be a useful and insight provoking discussion.

\section{Conclusion}

In summary, in this article we described two examples of clinical legal education attempts to make law school a more useful and less alienating environment for Indigenous students. We also described an experience of trying to educate non-Indigenous students about working with Indigenous clients and communities and reflected on the challenges and issues it triggered for us.

Clinical legal education can be a valuable approach to address the feelings of alienation of Indigenous students and one which other law schools could emulate. Clinical courses help students to ground legal concepts, and have the potential to reaffirm the reasons they chose to study law in

27 O’Donnell, above n 21 quoting Jamrozik A, Boland $\mathrm{C}$ and Urquhart R, Social Change and Cultural Transformation in Australia, (1995), Cambridge
University Press: Victoria, p xi

28 O'Donnell, above n 21, 142. 
the first place. For students who might otherwise be marginalised or excluded, this is particularly important. The very positive experience of first year Indigenous students of early clinical courses raises the larger question of the value of clinical legal education for ALL law students, early on in their degrees. The evaluations of these courses demonstrate the benefits to students of doing clinical courses early in their degree programs. They increase their commitment to their studies, and to the practice of law for the benefit of the community. It also grounds their legal studies and makes the theory more alive through real client experiences. While providing clinical experiences for all law students early on in their degrees would be valuable, it would require a greater dedication of resources than is likely at this point in any University in Australia. At least the value of clinical legal education has been recognised at UNSW as vital for Indigenous first year students. And from this experience, we argue that the provision of clinical courses early on is particularly valuable for disadvantaged students at risk of withdrawing from law. Ensuring that disadvantaged students, including Indigenous students, can participate in legal studies, can only enrich the overall learning experience for other students and for the Faculty more broadly.

Supporting Indigenous students is however just one part of the response to the needs of Indigenous students. The other is developing and modifying curriculum in all courses to take account of Indigenous perspectives and for all students to be more inclusive of Indigenous points of view and be challenged to think more deeply about culture and race.

"From a teaching perspective, it is imperative to understand that the law we teach has grossly impacted on Indigenous peoples' lives and ways of being in this country. Academics need to remember that disputes over the legal validity and history of Australian colonisation, widespread mistreatment of Indigenous people following the European invasion, and unequal treatment under the law remain understandable sources of contention between Indigenous and non-Indigenous people to this day." 29

Students need to hear Indigenous voices directly. Challenging non-Indigenous students about where Indigenous communities and clients are within society and how to work with them has proven difficult. This involves challenging the ways in which non-Indigenous students expect to be taught about law and preparing them to hear stories of entrenched injustice and racism as an issue in current Australia. Working with clients in clinical courses provides a direct means of challenging students views about Indigenous clients and encouraging them to be tolerant and non judgemental. This is unique within the legal curriculum.

"It is through the possibility of Aboriginalising our legal education that we could bring another way of knowing the world and its legal systems, and thereby introduce students to other ways of coming to know the law." 30

It is both the how and the what which will change if we truly Aboriginalise our legal education. While some attempts have been made to do this in clinical courses, ILEC continues to have much work to do to ensure that all the law courses truly reflect Indigenous points of view at UNSW. This is part of a larger project and continues to be a work in progress. 